\title{
IMPRESSORAS 3D: UMA MUDANÇA NA DINÂMICA DO CONSUMO
}

\section{D printers: a change in consumer dynamics \\ Las impresoras 3D: un cambio en la dinámica de consumo}

\section{Cristiano Max Pereira Pinheiro}

Universidade Feevale, Rio Grande do Sul, Brasil.

Doutor em Comunicação Social pela Pontifícia Universidade Católica do Rio Grande do Sul. Coordenador do Laboratório de Criatividade e professor do mestrado em Indústria Criativa na Universidade Feevale.

E-mail:maxrs@feevale.br

\section{Gabriela Ehlers Mota}

Universidade Feevale, Rio Grande do Sul, Brasil.

Graduada em Moda pela Universidade Feevale.

E-mail: gabi.ehlers.m@gmail.com

\section{Camilla Steinhaus}

Universidade Feevale, Rio Grande do Sul, Brasil.

Graduada em Moda pela Universidade Feevale.

E-mail: camillasteinhaus@gmail.com

\section{Mikaela de Souza}

Universidade Feevale, Rio Grande do Sul, Brasil.

Graduada em Design Gráfico pela Universidade Feevale. Bolsista do Laboratório de Criatividade.

E-mail: mikaela@feevale.br

RESUMO Este artigo tem como tema a mudança no modo de consumir produtos e/ou ideias, gerada pela maior acessibilidade financeira das impressoras 3D. A questão norteadora deste estudo reflete sobre a mudança nos processos de projetar, fabricar e consumir diversos objetos devido ao uso desses equipamentos. Para apresentar um panorama inicial, optou-se por uma metodologia baseada em uma pesquisa exploratória de cunho bibliográfico. Obras de autores como Anderson e Gorni, publicadas respectivamente em 2012 e 2013, fundamentam a análise.

PALAVRAS-CHAVE Impressoras 3D, Dinâmica de consumo, Propriedade intelectual, Economia criativa.

ABSTRACT This article is about the change in the ways of consuming products and /or ideas, generated by the increasing financial affordability of 3D printers. The guiding question of this study reflects on the change in the process of designing, manufacturing and consuming various objects due to the use of these equipments. In order to present an initial overview, a methodology based on an exploratory bibliographic research was chosen. Works of authors such as Anderson and Gorni, respectively published in 2012 and 2013, was used to base the analysis.

KEYWORDS 3D Printers, Consumption dynamics, Intellectual property, Creative economy.

RESUMEN Este artículo tiene como tema el cambio en la manera de consumir productos e/o ideas generadas por la mayor accesibilidad financiera de las impresoras 3D. La cuestión principal de este estudio reflexiona sobre el cambio en el proceso de diseño, fabricación y consumo de diversos objetos debido a la utilización de este equipamiento. Para presentar un panorama inicial, se optó por una metodología basada en pesquisa exploratoria de carácter bibliográfico. Obras de autores como Anderson y Gorni, publicadas en 2012 y 2013, respectivamente, fundamentan el análisis.

PALABRAS CLAVE Impresoras 3D, Consumo dinámico, Propiedad intelectual, Economía creativa.

Como citar este artigo:

PINHEIRO, C. M. P.; MOTA, G. E: STEINHAUS, C: SOUZA, M. Impressoras 3D: uma mudança na dinâmica do consumo. Signos do Consumo, São Paulo, v. 10, n. 1, p. 15-22, jan./jun. 2018. 


\section{INTRODUÇÃO}

Há mais de trinta anos vêm sendo estudadas e desenvolvidas máquinas capazes de criar objetos em três dimensões de uma só vez. Por volta do ano de 2006, esse tipo de técnica já ensaiava suas primeiras aplicações em nível pessoal. Nessa época, o site Fab@Home ${ }^{1}$, ou "Fabricação em casa", em tradução livre, instruía as pessoas sobre a manufatura aditiva e tinha como a principal função promover a comercialização e o uso da primeira impressora tridimensional voltada para uso doméstico (GORNI, 2013).

Atualmente, estão disponíveis no mercado internacional e no brasileiro diversas opções de impressoras 3D com preços acessíveis. Nos últimos anos, muitas empresas locais têm se dedicado à fabricação de suas próprias máquinas e ao desenvolvimento de hardware e software de código aberto. Esse projeto, denominado Metamáquina, resultou na disponibilidade de impressoras 3D a preços bastante acessíveis (GORNI, 2013).

O efeito que a popularização das impressoras 3D irá trazer ainda é incerto, mas já são feitas algumas suposições baseadas nas primeiras revoluções industriais e na forma como essas máquinas estão sendo utilizadas hoje. A transformação provocada pelo maior acesso a computadores estende a produção de objetos, abrangendo não só os atuais fabricantes, mas também pessoas comuns que estão virando empreendedores. Apesar do aumento significativo da economia criativa e dos bens intangíveis na forma de propriedade intelectual, essa nova revolução está apenas começando.

Dessa forma, este ensaio tem como tema a mudança no modo de consumir produtos e/ou ideias, gerada pela maior acessibilidade financeira das impressoras 3D. Busca-se ainda responder à questão que o norteia, que reflete sobre a mudança no processo de projetar, fabricar e consumir diversos objetos devido ao uso desses equipamentos. $\mathrm{O}$ trabalho foi organizado de forma que, após a introdução, é abordado o tema sobre a tecnologia das impressoras 3D, trazendo um breve entendimento de como funciona e como está sendo utilizada. No tópico seguinte, será tratado o tema da dinâmica de consumo e como ela está se modificando, bem como o aumento na oferta de modelos e ideias. Ao final deste artigo, será abordado o tema da economia criativa e como a dinâmica de consumo se relaciona com as lógicas desse setor, através de uma metodologia de pesquisa exploratória de cunho bibliográfico com autores como Anderson (2012) e Gorni (2013), que fundamentam a análise.

\section{AS IMPRESSORAS 3D: FUNCIONAMENTO E UTILIZAÇÕES}

Técnicas de fabricação de objetos tridimensionais já vêm sendo elaboradas desde o século passado. As primeiras impressoras 3D foram pensadas e desenvolvidas primeiramente para a manufatura rápida. Após quinze anos do princípio desses estudos, surgiram empresas oferecendo serviços de prototipagem rápida ou de manufatura em pequena escala, feitas com esse tipo de máquinas. Assim, foi-se estudando e desenvolvendo maneiras de aprimorar tais máquinas, até que, por volta dos anos 2000, já estavam disponíveis no mercado impressoras 3D a preços razoáveis, que permitiram suas primeiras aplicações a nível pessoal (GORNI, 2013).

1. Disponível em: <https://goo.gl/gxuxSp>. Acesso em: 24 jan. 2017. 
O funcionamento das impressoras 3D é bastante similar ao das impressoras comuns usadas no dia a dia, sendo que suas diferenças dizem respeito apenas ao tipo de material ejetado e ao motor, que conta com um a mais para controlar a altura do produto. Segundo Anderson (2012), a impressora 3D está hoje no mesmo patamar do Macintosh ${ }^{2}$ e a LaserWriter ${ }^{3}$ estavam há 20 anos. Não se sabe ainda como e para que exatamente elas serão utilizadas, pois ainda estão em fase de experimentação, e apenas uma parcela muito pequena da população possui esse tipo de equipamento em casa. Espera-se que, daqui a alguns anos, o uso dessa ferramenta se torne tão onipresente e intuitivo como o das impressoras a jato de tinta.

As técnicas para produzir objetos em três dimensões partem de um mesmo princípio. Primeiramente, é necessário ter um modelo tridimensional do objeto em meio digital. Através dos softwares de CAD (Computer Aided Design), o objeto é desenvolvido e preparado para ser impresso. A impressora ligada ao computador que possui o software utiliza um dispositivo mecânico para dispor e unir minúsculas partículas de um ou mais materiais em finas camadas. Essas camadas são sobrepostas uma a uma formando, assim, o objeto desejado, podendo ele ser oco ou maciço (MATSUURA, 2013).

Para criar o molde que será impresso, é possível utilizar duas técnicas. Uma delas é a criação do objeto 3D em um software, mas essa técnica exige conhecimentos mais aprofundados sobre o programa e sobre modelagem digital. A segunda técnica permite a obtenção do molde através de um escaneamento do objeto a ser copiado. Esse escaneamento pode ser feito por smartphone, tablet ou kinect $t^{4} \mathrm{e}$ é mais utilizado pela fabricação doméstica (MATSUURA, 2013).

Podemos visualizar as impressoras 3D através de três eixos: o primeiro eixo move a impressora para os lados, o segundo controla o movimento para a frente e para trás e o terceiro, que é o que difere a impressora 3D das impressoras comuns, é responsável por controlar os movimentos de baixo para cima. Os três tipos de impressoras 3D mais comuns são as que funcionam por fusão e deposição (Fused Deposition Modeling - FMD), as de estereolitografia (Stereo Lithography Apparatus - SLA) e as que funcionam com sinterização seletiva a laser (Selective Laser Sintering - SLS). Todas elas são máquinas aditivas, ou seja, constroem os objetos camada por camada, de baixo para cima (ANDERSON, 2012).

As impressoras que funcionam por FMD esguicham plástico ABS por um pequeno orifício, depositando-o em camadas. As máquinas SLA são mais sofisticadas que as anteriores e utilizam laser para endurecer a resina líquida. Por fim, as impressoras que funcionam por SLS também utilizam laser, mas os materiais para compor o objeto podem ser plástico, metal, ou cerâmica em pó. O software é responsável por analisar o arquivo CAD e determinar como ele será impresso, fatiando o objeto em finas camadas (o máximo que a impressora consegue manipular) e desenvolve uma estrutura de apoio que tenha o máximo de rigidez com o mínimo de material necessário (ANDERSON, 2012).

Existem outras possibilidades para construir objetos além das impressoras 3D. Uma delas são as máquinas CNC, que, ao contrário das

2. Primeiro computador pessoal a popularizar a interface gráfica através de um processo revolucionário para a época.

3. Impressora a laser produzida pela marca Apple em 1985.

4. Sensor de movimentos desenvolvido para a utilização em jogos de videogame, que dispensa o uso de controles. 
impressoras, fazem uso do método subtrativo, em que retiram material para formar o objeto. É como a criação de uma escultura, em que a máquina parte de um bloco da matéria-prima, geralmente plástico, madeira ou metal, e vai esculpindo esse material para formar o objeto desejado. Esse tipo de máquina também é utilizado para patchwork, bordado, corte de letreiros ou serigrafia. Outra opção para fazer objetos em três dimensões é o uso das cortadoras a laser. Essas cortadoras trabalham da mesma forma que as impressoras jato de tinta, mas ao invés de formar figuras ou frases no papel, cortam o material. Assim, pode ser utilizado para cortar objetos 2D e formar encaixes para que ele se torne um objeto 3D (ANDERSON, 2012).

Além da elaboração do objeto e das ferramentas necessárias para imprimi-lo, outro item indispensável para a impressão 3D são as matériasprimas. Hoje é possível utilizar diversos materiais, como ferro, aço, ouro, diversos polímeros, vidro e chocolate. Em âmbito doméstico, são produzidos pequenos objetos, como capas para celulares, pequenos vasos de plantas, xícaras, entre outros. Já os produtos desenvolvidos por empresas e indústrias, que utilizam impressoras com maior capacidade e softwares mais avançados, podem ser desde peças para automóveis e roupas até próteses médicas de alta qualidade (CUNHA, 2013).

Atualmente já é possível imprimir órgãos humanos com células vivas. Na medicina, próteses dentárias e aparelhos ortodônticos são feitos a partir de um molde da boca do paciente. Mandíbulas inteiras foram substituídas por próteses impressas em titânio. Objetos impressos são utilizados para prototipagem em praticamente todos os tipos de dispositivos. Nas áreas da arquitetura e engenharia civil, as impressoras estão sendo muito utilizadas para construir maquetes de casas e prédios (ANDERSON, 2012).

Pensando no futuro da impressão 3D, profissionais estudam meios para desenvolver uma impressora capaz de construir prédios de concreto, utilizando o mesmo princípio das impressoras atuais, mas em uma escala muito maior. Ao mesmo tempo, pesquisadores trabalham para desenvolver uma impressora 3D em nível molecular. A expectativa para o futuro dessas impressoras é que elas tragam mudanças revolucionárias equivalentes às mudanças ocorridas pelo surgimento da produção em massa (ANDERSON, 2012).

Por ser uma ferramenta nova, a impressão 3D ainda é carente em alguns aspectos, como a baixa velocidade na construção, a falta de especificações técnicas, a falta de dados das propriedades dos materiais, o mau acabamento da superfície e a porosidade. Alguns desses problemas, entretanto, já vêm sendo estudados e solucionados: um exemplo é a American Society for Testing Materials $^{5}$ (ASTM), que está trabalhando para normatizar os aspectos ligados à manufatura aditiva, como métodos de ensaio, processos, materiais, design e terminologia. Assim que esses processos forem normatizados, a falta dos dados sobre os materiais também será solucionada (GORNI, 2013).

\section{AS MUDANÇAS NA DINÂMICA DE CONSUMO}

É intrínseco a todos os seres humanos necessidades, desejos, habilidades e ideias. Durante todo o século XX, a variedade de produtos oferecidos ao consumidor final era limitada pela capacidade de carregamento dos sistemas de distribuição tradicionais das lojas físicas, sendo que a variedade limitada das lojas de antigamente "refletia as características econômicas do

5. Órgão estadunidense de normalização. 
varejo da época, e não a verdadeira diversidade das preferências humanas" (ANDERSON, 2012, p. 72). Porém, com o surgimento da internet, essas limitações começaram a desaparecer, uma vez que o "espaço na prateleira" é ilimitado e o aumento na demanda surge como consequência, eliminando antigos monopólios.

Do ponto de vista prático, qualquer sociedade utiliza os materiais e as ferramentas a sua volta para se reproduzir física e socialmente. O que é consumido para saciar as necessidades básicas, físicas e biológicas é utilizado no sentido do esgotamento e também para conferir status e construir identidades entre grupos e pessoas. Outros bens que são usados pelos indivíduos para se reproduzir física e socialmente são consumidos para auxiliar nas descobertas ou na constituição da sua subjetividade e identidade (CAMPBELL; BARBOSA, 2006).

Tradicionalmente, o consumo é associado à exaustão e/ou aquisição de algo. Atualmente, a fruição e ressignificação de bens e serviços antes percebidos como experiências culturais são agrupadas sob o rótulo de consumo. Com isso, customizar uma roupa, seguir certa dieta alimentar e ouvir certo gênero musical é sinônimo de consumo no sentido de experiência, que constrói uma certa identidade ou pratica o autoconhecimento (CAMPBELL; BARBOSA, 2006).

De acordo com Campbell e Barbosa (2006), o consumismo moderno parte da própria demanda do consumidor, que depende da habilidade de exercitar continuamente seu desejo por bens e serviços. Um aspecto característico do consumo moderno, segundo o autor, é que produtos e serviços são comprados pelos indivíduos para o uso próprio, diferentemente das décadas passadas, nas quais os objetos eram consumidos mais pela necessidade do que pelo desejo e eram visados para um uso mais comunitário do que individual.

Outra grande mudança na dinâmica de consumo é o aumento no tempo dedicado ao consumo de conteúdo amador ao invés do profissional. A internet e, principalmente, as redes sociais, abrem espaço para que as pessoas possam divulgar, compartilhar, trocar e até vender suas ideias sem precisarem de nenhum intermediário ou de um grande investimento. $\mathrm{O}$ uso da internet também possibilita que qualquer pessoa possa criar peças para o próprio uso (ANDERSON, 2012).

Concomitantemente, as fábricas ao redor do mundo também modificam sua maneira de produzir e comercializar seus produtos a fim de se atualizarem e continuarem no mercado. Muitas empresas têm aberto suas portas oferecendo um serviço de fabricação pela web, sendo necessário apenas um cartão de crédito e o design do produto desejado para que uma pessoa possa concretizar suas ideias (ANDERSON, 2012).

Baudrillard (1970) afirma que os bens não são consumidos única e exclusivamente por si próprios, mas sim pelo seu significado em relação a determinados sistemas de valores. As necessidades humanas hoje buscam suprir os valores que os objetos possuem e a satisfação ao adquiri-los antes da própria funcionalidade de tal objeto.

Um exemplo de projeto de produto que mudou devido à sua associação com a internet e que, por sua vez, está fazendo parte da mudança na dinâmica de consumo são os irrigadores de jardins. No seu livro Makers: a nova revolução industrial, Chris Anderson (2012) dá um exemplo de como esses produtos evoluíram não só como produtos físicos mas também mudaram no modo de comercialização e divulgação.

Anderson (2012) relata que, por volta da década de 1940, seu avô materno, Fred Hauser, desenvolveu um sistema de irrigação de jardins automático. 
Na época, não existia no mercado sistema semelhante, por isso Hauser patenteou seu produto. Com a patente, ele procurou alguma indústria que estivesse disposta a comprar o seu projeto, produzir e vender o produto. Em 1950, uma empresa interessou-se pelo projeto, e o produto começou a ser comercializado. Fred Hauser recebeu royalties da sua patente até a década de 1970, quando a patente venceu e os produtos comercializados pouco se assemelhavam com os primeiros rascunhos do inventor.

A partir da saga de seu avô para produzir e comercializar sua patente, Anderson buscou fazer a mesma coisa, mas com as ferramentas atuais. Ele cria então um novo sistema de regadores automáticos conectados à internet. A diferença relatada por Anderson é manifestada na maneira como essas duas ideias, uma do século XX e outra do século XXI, chegam ao consumidor final. Atualmente, a internet possibilita que qualquer projeto possa se espalhar pelo mundo todo. Com essa abertura do mercado, a concorrência ficou mais acirrada, e são as empresas que buscam ideias para produzir, e não o contrário.

Assim, Anderson (2012) consegue transformar suas ideias em produtos muito mais rapidamente do que o seu avô no século passado. Da mesma forma, qualquer pessoa disposta a colocar suas ideias na rede pode comercializar seus produtos sem grandes burocracias, visto que o mundo hoje se encontra "assistindo à inovação de baixo para cima, promovida por inúmeros indivíduos, abrangendo amadores, empreendedores e profissionais” (ANDERSON, 2012, p. 35).

\section{IMPRESSORAS 3D, ECONOMIA CRIATIVA E A DINÂMICA DE CONSUMO}

Com o surgimento dessa nova dinâmica, cada vez mais se ouve falar em economia criativa. Essa nova definição de economia consiste, basicamente, nas transações feitas a partir de produtos criativos. Segundo Howkins (2013), os produtos criativos são aqueles que provém de setores ligados a direitos autorais, como propaganda, softwares, design, fotografia, filmes, vídeos, artes cênicas, música, rádio/TV e videogames.

A economia da criatividade se baseia em dois sistemas diferentes, em que um deles se refere a bens e objetos tangíveis e o outro se refere à propriedade intelectual. Essa propriedade intelectual antes vista muito mais como ideias patenteadas ganha mais espaço nos dias atuais devido aos novos meios de comunicação. Atualmente, essas ideias que não são patenteadas encorajam outras pessoas com ideias semelhantes a aperfeiçoar seus próprios conhecimentos e suas próprias habilidades (HOWKINS, 2013).

Há muitas razões para que no século XXI a economia criativa se torne a forma econômica dominante. Isso se deve aos diversos processos de automação que estão em andamento e à crescente busca de trabalhos nos setores criativos. Fala-se que, hoje em dia, a produção depende cada vez mais de recursos intangíveis, e juntamente com "o baixo custo da tecnologia digital, permite-se às pessoas produzirem, distribuírem e trocarem seus próprios materiais e cada vez mais penetrando por todos os grandes mercados corporativos" (HOWKINS, 2013, p. 19).

Assim, há grandes indícios de uma tendência cada vez maior a rejeitar tanto a autoridade da tradição quanto a dos especialistas, dando espaço para os indivíduos fazer valer seus desejos, vontades e preferências (CAMPBELL; BARBOSA, 2006). Espera-se que daqui a alguns anos todas as pessoas tornemse criadoras, devido ao potencial que já é presente nos seres humanos e às novas ferramentas digitais que estão surgindo. Em breve, especula-se que 
essas ferramentas se tornem onipresentes e intuitivas, assim como outras que já passaram pelo mesmo processo de democratização (ANDERSON, 2012).

A lei de patentes criada por Thomas Jefferson e outros fundadores foi concebida com o objetivo de compartilhar as novas invenções com toda a população. Por isso, até hoje é necessário publicar tais invenções para que estas sejam licenciadas. Cada vez mais os criadores compartilham suas ideias através dos códigos abertos. O papel das impressoras 3D na economia criativa é colaborar para que as pessoas usem as redes de compartilhamento de ideias para criar e construir projetos de forma cooperativa, transformando a indústria criativa e abrindo o mercado para qualquer pessoa que tenha uma boa ideia (ANDERSON, 2012).

Chris Anderson no seu livro Makers: a nova revolução industrial (2012) apresenta duas hipóteses para a economia impulsionada pelo movimento maker, nas quais todos criam e projetam diversos objetos para os mais variados usos. A primeira delas é o fim das grandes indústrias e o surgimento de várias outras empresas menores atuando em nichos de mercado muito mais diferenciados. A segunda é que grande parte do conteúdo será criado por amadores sem intenção de construir empresas e gerar lucros.

Essa segunda hipótese tem mais a ver com a autossuficiência, em que as coisas são feitas para o próprio uso, excluindo as grandes empresas e buscando uma "libertação", de modo que as pessoas poderão fazer downloads de projetos e imprimi-los em sua casa sem que seja necessária qualquer transação financeira (ANDERSON, 2012).

Pensando em uma ou duas décadas a frente, podemos visualizar impressoras 3D mais rápidas e silenciosas e com uma gama ainda maior de matérias-primas. Com a democratização dos serviços de fabricação de produtos, empresas, governos e outras instituições perdem o domínio exclusivo de setores de atividades, provocando assim mudanças revolucionárias (ANDERSON, 2012).

\section{CONSIDERAÇÕES FINAIS}

As impressoras 3D estão ganhando cada vez mais espaço no ambiente doméstico ao redor de todo o mundo. Com elas, é possível materializar quase qualquer objeto, sendo necessário apenas o projeto e as ferramentas para produzi-lo. Com o surgimento dessas máquinas, espera-se que o compartilhamento de ideias, como já é possível perceber no cenário atual, aumente ainda mais.

A dinâmica de consumo hoje se resume em bens e serviços tangíveis. Com o advento das impressoras 3D, essa dinâmica está mudando. Os projetos e modelos para impressão 3D estão sendo comercializados e vendidos como ideias, e não como objetos. Assim, à medida que as impressoras 3D vão ocupando lugar nas casas das pessoas, estas passarão a consumir mais ideias (em forma de projetos) do que os objetos em si.

Além da comodidade de não precisar sair de casa para adquirir um novo produto, as impressoras 3D proporcionam um maior envolvimento do consumidor com o produto, podendo projetá-lo da maneira que lhe convém. Empresas estão surgindo com o intuito de oferecer o serviço de modelagem e impressão 3D para que cada pessoa possa customizar os objetos à sua maneira. Essas empresas também estão se especializando em nichos de mercado com produtos mais especializados graças às impressoras 3D, que podem fabricar os mais variados objetos de acordo com o cliente e sem a necessidade de estoque. 


\section{REFERÊNCIAS}

ANDERSON, C. Makers: a nova Revolução Industrial. São Paulo: Elsevier Campus, 2012.

BAUDRILLARD, J. A sociedade de consumo. São Paulo: Edições 70, 1970. v. 54. (Coleção Arte e Comunicação).

CAMPBELL, C.; BARBOSA, L. Cultura, consumo e identidade. Rio de Janeiro: FGV Editora, 2006.

CUNHA, H. A. Impressoras 3D: o direito da propriedade intelectual precisará alcançar novas dimensões? 2013. 46 f. Trabalho de conclusão de curso (Graduação em Direito) Fundação Getúlio Vargas, Rio de Janeiro, 2013.

HOWKINS, John. Economia Criativa: como ganhar dinheiro com ideias criativas. São Paulo: M. Books, 2013.

GORNI, A. A. Prototipagem rápida, a revolução 3D. Plástico Industrial, São Paulo, nov. 2013. Disponivel em: <https://goo.gl/qDRQw2>. Acesso em: 30 out. 2016.

MATSUURA, S. Brinquedos, carros e casas impressos em 3D. O globo, Rio de Janeiro, 7 abr. 2013. Disponível em: <https://goo.gl/Ctmm6f>. Acesso em: 30 out. 2016.

TAKAGAKI, L. K. Tecnologia de impressão 3D. RIT: Revista Inovação Tecnológica, São Paulo, v. 2, n. 2, p. 28-40, 2012. 